\title{
Respuesta de la embriogénesis somática directa en tres regiones foliares de Phalaenopsis amabilis
}

\section{Response of direct somatic embryogenesis in three leaf regions of Phalaenopsis amabilis}

David Isauro De La Cruz Cáceres ${ }^{1}$, María Emilia Ruiz Sánchez ${ }^{1}, J_{u a n}$ Carlos Guerrero-Abad ${ }^{1 *}$

\section{RESUMEN}

Fue explorado el efecto de ácido naftalenacético (ANA) y 1-fenil-3-(1,2,3-tiadiazol-5-il)urea (TDZ) en segmentos de hojas inmaduras de Phalaenopsis amabilis. Para este experimento, se emplearon tres regiones foliares de $12 \times 1.7 \mathrm{~mm}$ (basal, medial y apical) sobre diferentes concentraciones de ANA $(0.00 ; 0.53$ y $5.37 \mu \mathrm{M})$ y TDZ $(0,00$; $0,45 ; 4,50$ y 13,60 $\mu \mathrm{M})$, acompañado de sales minerales Murashige y Skoog (1962) y suplementado con 10,0 mg/L Myo-inositol, 0,5 mg/L Pyridoxine, $0,1 \mathrm{mg} / \mathrm{L}$ Thiamine, $2,0 \mathrm{mg} / \mathrm{L}$ Glycine, $170,0 \mathrm{mg} / \mathrm{L} \mathrm{NaH}_{2} \mathrm{PO}_{4}, 2,0 \mathrm{~g} / \mathrm{L}$ Peptona, $20,0 \mathrm{~g} / \mathrm{L}$ de Sacarosa y 3,75 g/L de Agar, ajustado a un pH 5,2. Segmentos foliares fueron incubados en oscuridad sobre diferentes concentraciones y combinaciones hormonales por un lapso de 30-45 días y luego sometidos a luz. El porcentaje de inducción de callos evaluados en los tratamientos en estudio demuestra que a los 30 días de inducción existe un $100 \%$ de reactividad callogénica. La aparición de estadios globulares pro-embrionarios en segmentos de hoja de Phalaenopsis amabilis, fue posible en los tratamientos $\mathrm{T}_{1}, \mathrm{~T}_{2}, \mathrm{~T}_{5}$ y $\mathrm{T}_{6}$. De forma interesante la mayor formación de estructuras somáticas pro-embrionarias estuvieron presentes en la región basal, sin la necesidad de la adición independiente o combinatoria de ANA o TDZ. Sin embargo, la mayor cantidad de plantas regeneradas tan solo fue posible en estructuras pro-embrionarias de la región basal, conteniendo $0,53 \mu \mathrm{M}$ de ANA.

Palabras clave: Phalaenopsis amabilis., ácido naftalenacético, thidiazurón, segmento foliar.

\section{ABSTRACT}

It was explored the effect of 1-naphthaleneacetic acid (ANA) and 1-phenyl-3-(1, 2, 3-tiadiazol-5-il) urea (TDZ) in immature leaf segments of Phalaenopsis amabilis. For this experiment, three foliar regions of $12 \times 1.7 \mathrm{~mm}$ were used (basal, medial and apical) on different concentrations of ANA $(0.00 ; 0.53$ and $5.37 \mu \mathrm{M})$ and TDZ $(0.00 ; 0.45 ; 4.50$ and $13.60 \mu \mathrm{M}$ ), with Murashige y Skoog mineral salts (1962) and supplemented with $10.0 \mathrm{mg} / \mathrm{L}$ Myo-inositol, 0.5 $\mathrm{mg} / 1$ Pyridoxine, $0.1 \mathrm{mg} / 1$ Thiamine, $2.0 \mathrm{mg} / 1$ Glycine, $170.0 \mathrm{mg} / 1 \mathrm{NaH}_{2} \mathrm{PO}_{4}, 2.0 \mathrm{~g} / \mathrm{L}$ Peptone, $20.0 \mathrm{~g} / \mathrm{L}$ sucrose and $3.75 \mathrm{~g} / \mathrm{L}$ Agar, adjusted to $\mathrm{pH}$ 5.2. Leaf segments were incubated in darkness on different concentrations and hormonal combinations for a period of 30-45 days and then exposed to light. The percentage of callus induction evaluated in the treatments under study shows that $100 \%$ of callogenic reactivity was achieved at 30 days of induction. The emergence of pro-embryonic globular stages in leaf segments of Phalaenopsis amabilis, was possible in the treatments T1, T2, T5 and T6. Interestingly, the greater formation of somatic pro-embryonic structures were present in the basal region, without the need for the independent or combinatorial addition of ANA or TDZ. However, the largest number of regenerated plants was only possible in pro-embryonic structures of the basal region, containing $0.53 \mu \mathrm{M}$ of ANA.

Key words: Phalaenopsis amabilis., naftalenacético acid, thidiazuron, foliar segment.

\footnotetext{
${ }^{1}$ Laboratorio de Cultivo de Tejidos Vegetales, Facultad de Ciencias Agrarias, Universidad Nacional de San Martín(UNSM), Jiron Amorarca N ${ }^{\circ}$ 315, Tarapoto, Perú

"Autor de correspondencia. E-mail: jc.guerrero.abad@gmail.com
} 


\section{INTRODUCCIÓN}

El género Phalaenopsis representa el grupo más importante de orquídeas en el mundo en materia de comercialización y diversidad de híbridos selectos, por la durabilidad de sus flores en planta y flores de corte. A diferencia de otras orquídeas, su crecimiento monopodial lento ha dificultado su propagación asexual por brotación de híbridos sobresalientes, descartándose la posibilidad de propagarlas por la vía asexual (Gil, 1987). Entre los principales países productores de orquídeas cabe destacar Brasil, China, Costa Rica, Estados Unidos, Filipinas, Indonesia, Países Bajos y Tailandia. Alrededor del $75 \%$ de las orquídeas comercializadas a nivel mundial pertenecen al género Phalaenopsis. Estas son orquídeas sin pseudobulbo, tienen raíces largas, hojas suculentas y crecimiento monopodial. Sus flores están agrupadas de forma sincronizada, destacadas por su color blanco, rosa, malva o amarillo. Las mismas que se conservan en buen estado entre 6 a 10 semanas, convirtiéndolas en plantas ornamentales apropiadas para interior (Harper, 2004).

El cultivo de tejidos vegetales, como técnica, consiste esencialmente en aislar una porción de la planta y brindarle las condiciones físicas y químicas de forma artificial con el fin de que las células expresen su potencial intrínseco o inducido (Thorpe, 1981). Protocolos convencionales de propagación in vitro han sido desarrollados en el género Phaleanopsis y usualmente con el propósito de su propagación (Tanaka et al., 1975; Arditti y Ernst, 1993; Ernst, 1994; Chen y Piluek, 1995; Duan et al., \}1996; Ishii et al., 1998; Islam y Ichihashi, 1999; Chen et al., 2000; Young et al., 2000; Tokuhara y Mii, 2001; Park et al., 2002). Todos ellos buscando generar protocormos a partir de semilla sexual. Protocolos de propagación vía embriogénesis somática, una vía asexual que asegura la regeneración de plantas completas, fueron realizados en Phaleanopsis empleándose diferentes concentraciones de ácido naftalenacético (ANA) y 1fenil-3-(1,2,3-tiadiazol-5-il)urea (TDZ), utilizándose fragmentos enteros de hojas inmaduras (Chen y
Chang, 2006; Gow et al., 2010). A diferencia de las investigaciones anteriores, el propósito de la presente investigación fue determinar la región foliar más activa de respuesta a la embriogénesis somática de pequeños fragmentos foliares sobre la presencia de ácido naftalenacético (ANA) y 1-fenil-3-(1,2,3tiadiazol-5-il)urea (TDZ). Nuestros resultados sugieren que la región más activa a la embriogénesis somática directa en Phaleanopsis amabilis, es la región basal, con una probable participación endógena de reguladores de crecimiento.

\section{MATERIALES Y MÉTODOS}

\section{Material vegetal y condiciones de crecimiento}

Hojas inmaduras de Phalaenopsis amabilis, obtenidas a partir de plantas propagadas por semillas durante siete meses fueron seccionadas como material inicial. El segundo par de hojas de Phaleanopsis fueron seleccionadas para segmentar pequeños explantes de $12 \times 1,7 \mathrm{~mm}$ de tres regiones: basal, medio y apical. Tres fragmentos/tubo de ensayo fueron inoculados en un medio de cultivo para la inducción de callos. Se preparó un medio de cultivo conteniendo sales minerales MS a 1/2 concentración suplementado con 20,0 mg/L Myo-inositol, 1,0 mg/L Pyridoxine, 0,20 mg/L Thiamine, 4,0 mg/L Glycine, 340,0 mg/L NaH${ }_{2} \mathrm{PO}_{4}, 4,0 \mathrm{~g} / \mathrm{L}$ Peptona, 40,0 g/L de sacarosa, 6,75 g/L de Agar - Agar fraccionada en 12 partes, a las cuales se les adiciono diferentes concentraciones de ácido naftalenacético (ANA) y thidiazurón (TDZ) de acuerdo a la combinación de los niveles de estudio (Tabla 1), ajustando a un pH de 5,2 para todos los tratamientos. $12 \mathrm{~mL}$ de medio de cultivo fueron dispuestos en tubos de ensayo de 25x150 mm. Los tubos de ensayo conteniendo el medio de cultivo fueron inclinados para formar un ángulo de $30^{\circ}$ hasta conseguir su gelificación.

\section{Diseño experimental}

Fue empleado un diseño completamente al azar con arreglo factorial $3 \times 4$ : Factor (A): ácido naftalenacético $(0,00 ; 0,53$ y $5,37 \mu \mathrm{M})$ y Factor $(\mathrm{B})$ : thidiazurón [1fenil-3-(1,2,3-tiadiazol-5-il)urea] $(0,00 ; 0,45 ; 4,50 \mathrm{y}$ $13,60 \mu \mathrm{M}$ ), donde cada unidad experimental (repeti- 
Tabla 1. Combinación de reguladores de crecimiento ANA $(0.00$; 0.53 y $5.37 \mu \mathrm{M})$ y TDZ $(0.00 ; 0.45 ; 4.50$ y $13.60 \mu \mathrm{M})$

\begin{tabular}{|c|c|c|c|}
\hline Tratamientos & Clave & $\begin{array}{l}\text { Factor (A) } \\
\text { ANA }[\mu \mathrm{M}]\end{array}$ & $\begin{array}{l}\text { Factor (B) } \\
\text { TDZ }[\mu \mathrm{M}]\end{array}$ \\
\hline $\mathrm{T} 1$ & $\mathrm{a} 1 \mathrm{~b} 1$ & 0.00 & 0.00 \\
\hline $\mathrm{T} 2$ & $\mathrm{a} 1 \mathrm{~b} 2$ & 0.00 & 0.45 \\
\hline T3 & a 1b3 & 0.00 & 4.50 \\
\hline $\mathrm{T} 4$ & $\mathrm{a} 1 \mathrm{~b} 4$ & 0.00 & 13.60 \\
\hline $\mathrm{T} 5$ & $\mathrm{a} 2 \mathrm{~b} 1$ & 0.53 & 0.00 \\
\hline T6 & $\mathrm{a} 2 \mathrm{~b} 2$ & 0.53 & 0.45 \\
\hline $\mathrm{T} 7$ & $\mathrm{a} 2 \mathrm{~b} 3$ & 0.53 & 4. 50 \\
\hline $\mathrm{T} 8$ & $\mathrm{a} 2 \mathrm{~b} 4$ & 0.53 & 13.60 \\
\hline T9 & a3b1 & 5.37 & 0.00 \\
\hline $\mathrm{T} 10$ & a3b2 & 5.37 & 0.45 \\
\hline $\mathrm{T} 11$ & a3b3 & 5.37 & 4. 50 \\
\hline $\mathrm{T} 12$ & a3b4 & 5.37 & 13.60 \\
\hline
\end{tabular}

ción) fue de 01 tubo de ensayo de 25 x 150 mm., con medio de cultivo inclinado conteniendo 03 segmentos foliares de diferentes regiones (base, medio y ápice) de $12,0 \times 1,7 \mathrm{~mm} /$ segmento. El experimento consistió de 12 tratamientos y 10 repeticiones.

\section{Parámetros de evaluación}

Para este estudio, fue evaluado la formación de callo en cada explante (callogénesis) hasta completar los 30 , 40 y 60 días de incubación. De la misma forma fue evaluado el número de estructuras proembrionarias en los fragmentos comprendidos por cada región de teji- do (basal, medial y apical), y finalmente fue cuantificado el número de plantas regeneradas por cada tratamiento y cada región foliar.

\section{RESULTADOS}

Segmentos foliares de Phaleanopsis de tres regiones (basal, medial y apical) de $12 \times 1,7 \mathrm{~mm}$, fueron obtenidos a partir de plántulas propagadas a partir de semilla botánica sobre condiciones in vitro (Figura 1). La incubación de estos segmentos sobre diferentes medios de cultivo (Tabla 1) generó una respuesta a la formación de callos a partir de los 30 días, incrementándose esta respuesta hasta los 60 días (Figura 2). Concentraciones endógenas propias del tejido en Phaleanopsis amabilis promueven una callogénesis en un $66,67 \%$ para la región basal y medial, y un 33\% para la región apical. La adición de $0.45 \mu \mathrm{M}$ de TDZ incrementa la callogénesis en un $100 \%$ para las tres regiones foliares aquí estudiadas (T2). Un escenario muy distinto fue constatado cuando se evaluó la respuesta de ANA en 0,53 y 5,37 $\mu \mathrm{M}$ (T5, T9), donde no se ha evidenciado una respuesta clara a la callogénesis. De igual manera, el incremento de TDZ de 4,50 a 13,60 $\mu \mathrm{M}$ disminuye la callogénesis (T3, T4). Nuestros resultados sugieren que existen respuestas endógeneas que promueven la callogenesis en segmentos foliares de Phaleanopsis amabilis, constatándose un posible gradiente decreciente de reguladores de crecimiento presente desde la base hasta el ápice de las

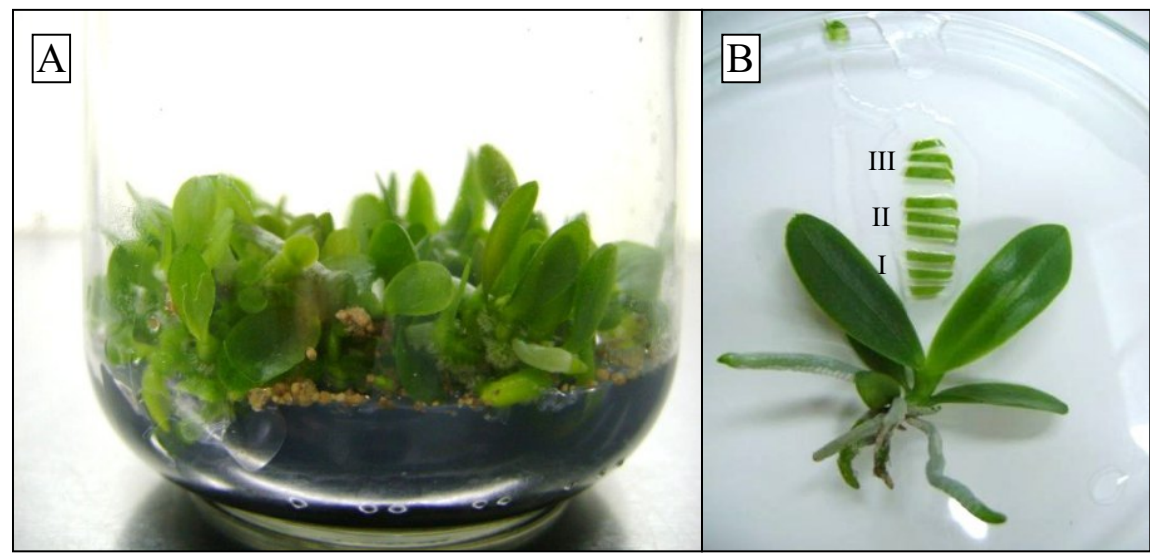

Figura 1. Vitroplantas de Phaleanopsis amabilis: A, plantas crecidas en frascos de 15 onzas por un periodo de 4 meses. B, Planta entera crecida por 6 meses, utilizada para el retiro de segmentos foliares de tres regiones: $\mathrm{I}=$ Basal, $\mathrm{II}=$ Medial y $\mathrm{III}=$ Apical . 

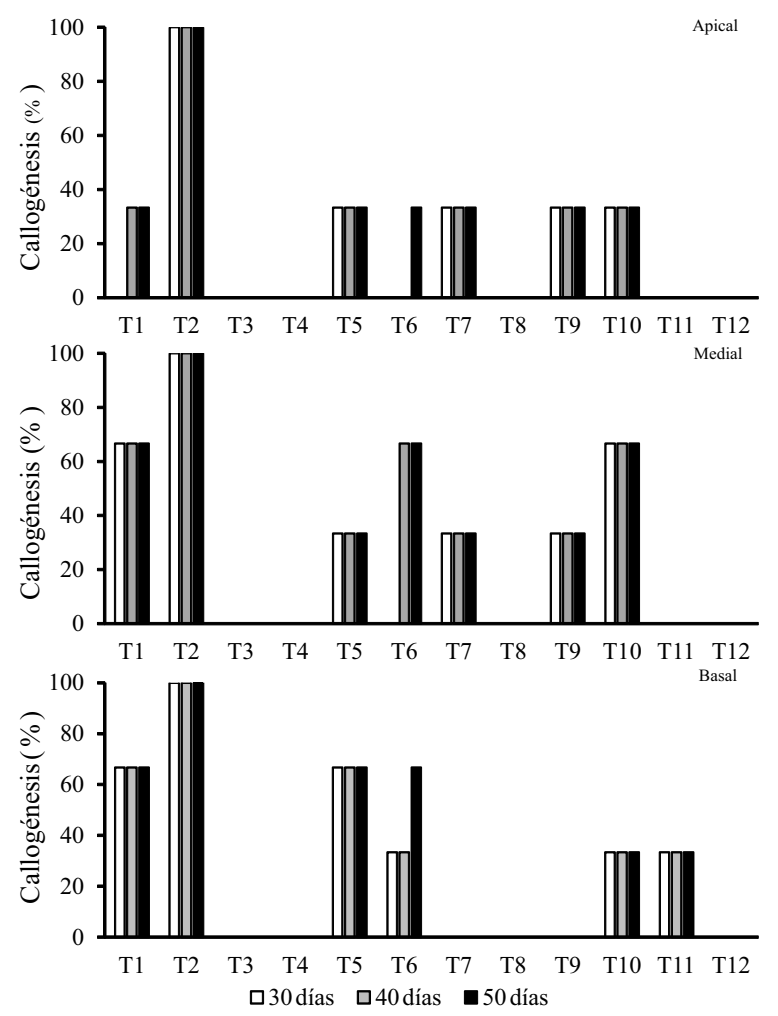

Figura 2. Respuesta de callogénesis en tres regiones foliares de Phaleanopsis amabilis (Basal, Medial y Apical) en la presencia de ANA y TDZ. La respuesta de callogénesis fue evaluada sobre diferentes concentraciones independientes y combinatorias de ANA y TDZ (T1, T2T12; Tabla 01), durante 30 (Barras blancas), 40 (Barras grises) y 60 (Barras negras) días respectivamente. hojas. De la misma forma, nuestros resultados sugieren que la adición de TDZ en concentraciones menores a $0,45 \mu \mathrm{M}$ potencializan la callogénesis.

Callos celulares son agrupamientos que pueden tener dos destinos, ser embriogénicos y no embriogénicos. El resultado de tener un callo embriogénico es su diferenciación a estructuras embrionárias, ampliamente caracterizadas en plantas modelo como Arabidopsis thaliana. Esta secuencia embrionária que deriva de células somáticas son muy semejantes a la embriogénesis zigótica, entre las transiciones más conocidas están las estructuras globulares, corazón, torpedo y cotiledonar, también conocidas como estructuras proembrionarias. Nuestro interés fue cuantificar estas estructuras pro-embrionarias en los segmentos foliares estudiados y nuestros resultados demuestran que segmentos foliares basales y mediales sobre condiciones endógenas promueven la formación de estructuras somáticas pro-embrionarias con un promedio de 12,67 y 8,67 pro-embrioides/segmento respectivamente. Un contraste muy diferente para segmentos foliares apicales (Tabla 2; T1). La adición de TDZ y ANA de forma creciente tiene una respuesta negativa en la formación de estructuras pro-embrionarias (Tabla 2; T2, T3, T4, T5 у T9).

Es bien conocido que la formación de estructuras pro-

Tabla 2. El efecto de ANA y TDZ en la formación directa de estructuras proembrionarias y regeneración de plantas a partir de segmentos foliares (Basal, Medial y Apical) de Phalaenopsis amabilis.

\begin{tabular}{cccccccc}
\hline & \multicolumn{4}{c}{$\mathrm{N}^{\circ}$ de pro -embrioides } & \multicolumn{3}{c}{$\mathrm{N}^{\circ}$ de plantas regeneradas } \\
\hline ANA & TDZ & \multicolumn{3}{c}{ Explante de hoja } & \multicolumn{3}{c}{ Explantedehoja } \\
\cline { 3 - 8 }$[\boldsymbol{\mu M}]$ & {$[\boldsymbol{\mu M}]$} & Basal & Medial & Apice & Basal & Medial & Apice \\
\hline 0,00 & 0,00 & $12,67 \pm 0,4^{\mathrm{a}}$ & $8,67 \pm 0,3^{\mathrm{a}}$ & $0,00 \pm 0,0^{\mathrm{c}}$ & $6,40 \pm 0,1^{\mathrm{c}}$ & $4,67 \pm 0,3^{\mathrm{a}}$ & $0,00 \pm 0,0^{\mathrm{b}}$ \\
0,00 & 0,45 & $7,67 \pm 0,3^{\mathrm{b}}$ & $3,00 \pm 0,1^{\mathrm{b}}$ & $1,33 \pm 0,1^{\mathrm{a}}$ & $2,67 \pm 0,3^{\mathrm{b}}$ & $3,00 \pm 0,1^{\mathrm{b}}$ & $0,00 \pm 0,0^{\mathrm{b}}$ \\
0,00 & 4,50 & $0,00 \pm 0,0^{\mathrm{d}}$ & $0,00 \pm 0,0^{\mathrm{c}}$ & $0,00 \pm 0,0^{\mathrm{c}}$ & $0,00 \pm 0,0^{\mathrm{c}}$ & $0,00 \pm 0,0^{\mathrm{c}}$ & $0,00 \pm 0,0^{\mathrm{b}}$ \\
0,00 & 13,60 & $0,00 \pm 0,0^{\mathrm{d}}$ & $0,00 \pm 0,0^{\mathrm{c}}$ & $0,00 \pm 0,0^{\mathrm{c}}$ & $0,00 \pm 0,0^{\mathrm{c}}$ & $0,00 \pm 0,0^{\mathrm{c}}$ & $0,00 \pm 0,0^{\mathrm{b}}$ \\
0,53 & 0,00 & $7,67 \pm 0,2^{\mathrm{b}}$ & $0,00 \pm 0,0^{\mathrm{c}}$ & $0,33 \pm 0,3^{\mathrm{b}}$ & $4,33 \pm 0,2^{\mathrm{a}}$ & $0,00 \pm 0,0^{\mathrm{c}}$ & $0,33 \pm 0,2^{\mathrm{a}}$ \\
0,53 & 0,45 & $4,67 \pm 0,3^{\mathrm{c}}$ & $0,00 \pm 0,0^{\mathrm{c}}$ & $0,00 \pm 0,0^{\mathrm{c}}$ & $3,33 \pm 0,2^{\mathrm{b}}$ & $0,00 \pm 0,0^{\mathrm{c}}$ & $0,00 \pm 0,0^{\mathrm{b}}$ \\
0,53 & 4,50 & $0,00 \pm 0,0^{\mathrm{d}}$ & $0,00 \pm 0,0^{\mathrm{c}}$ & $0,00 \pm 0,0^{\mathrm{c}}$ & $0,00 \pm 0,0^{\mathrm{c}}$ & $0,00 \pm 0,0^{\mathrm{c}}$ & $0,00 \pm 0,0^{\mathrm{b}}$ \\
0,53 & 13,60 & $0,00 \pm 0,0^{\mathrm{d}}$ & $0,00 \pm 0,0^{\mathrm{c}}$ & $0,00 \pm 0,0^{\mathrm{c}}$ & $0,00 \pm 0,0^{\mathrm{c}}$ & $0,00 \pm 0,0^{\mathrm{c}}$ & $0,00 \pm 0,0^{\mathrm{b}}$ \\
5,37 & 0,00 & $0,00 \pm 0,0^{\mathrm{d}}$ & $0,00 \pm 0,0^{\mathrm{c}}$ & $0,00 \pm 0,0^{\mathrm{c}}$ & $0,00 \pm 0,0^{\mathrm{c}}$ & $0,00 \pm 0,0^{\mathrm{c}}$ & $0,00 \pm 0,0^{\mathrm{b}}$ \\
5,37 & 0,45 & $0,00 \pm 0,0^{\mathrm{d}}$ & $0,33 \pm 0,2^{\mathrm{c}}$ & $0,00 \pm 0,0^{\mathrm{c}}$ & $0,00 \pm 0,0^{\mathrm{c}}$ & $0,00 \pm 0,0^{\mathrm{c}}$ & $0,00 \pm 0,0^{\mathrm{b}}$ \\
5,37 & 4,50 & $0,00 \pm 0,0^{\mathrm{d}}$ & $0,00 \pm 0,0^{\mathrm{c}}$ & $0,00 \pm 0,0^{\mathrm{c}}$ & $0,00 \pm 0,0^{\mathrm{c}}$ & $0,00 \pm 0,0^{\mathrm{c}}$ & $0,00 \pm 0,0^{\mathrm{b}}$ \\
5,37 & 13,60 & $0,00 \pm 0,0^{\mathrm{d}}$ & $0,00 \pm 0,0^{\mathrm{c}}$ & $0,00 \pm 0,0^{\mathrm{c}}$ & $0,00 \pm 0,0^{\mathrm{c}}$ & $0,00 \pm 0,0^{\mathrm{c}}$ & $0,00 \pm 0,0^{\mathrm{b}}$ \\
\hline
\end{tabular}

${ }^{a}$ Valores diferentes sobrescritos en una misma línea son estadísticamente diferentes de acuerdo al test de Tukey ( $\left.\mathrm{p}<0,01\right)$. 


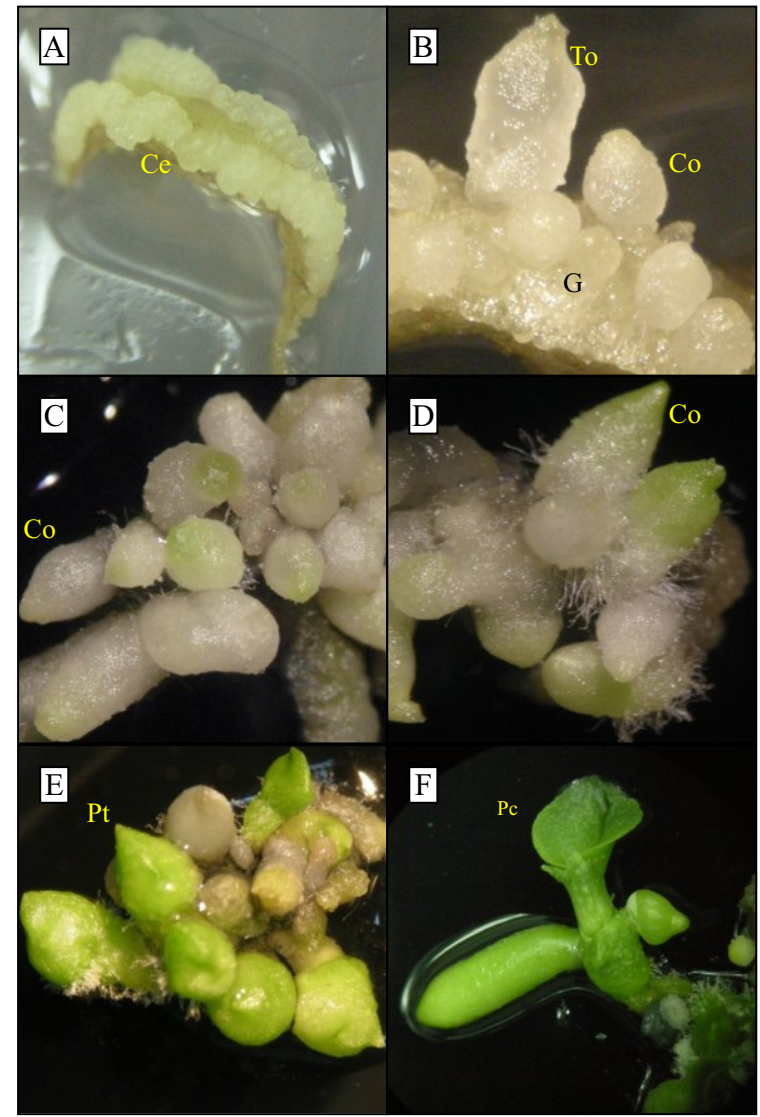

Figura 3. Caracterización de estructuras pro-embrionarias durante la formación de embriones somáticos. A, Segmento foliar basal con callo embriogénico (Ce) a los 40 días de inducción. B, Segmento foliar basal a los 45 de inducción con estructuras embriogénicas en estadio globular $(\mathrm{G})$, corazón (Co) y torpedo (To). C, D, Estructuras en estadio cotiledonar, tornándose protocormo $(\mathrm{Pt})$. D Transición de protocormos $(\mathrm{Pt})$ a plantas completas $(\mathrm{Pc})$, a los 160 dias de inducción $(\mathrm{F})$.

embrionarias anticipa la transformación de plantas completas, teniendo al estadio cotiledonar como el último estadio. De la misma forma que en estructuras pro-embrionarias, fue cuantificado el número de regenerantes totales/explante a nivel de cada tratamiento. Una vez más nuestros resultados demuestran que condiciones endógenas establecidas en los segmentos foliares basal y medial viabiliza la transformación de plantas completas en Phaleanopsis amabilis, con un promedio de 6,40 a 4,67 regenerantes/segmento (Tabla 2; T1), respectivamente. A diferencia de esta observación el empleo de concentraciones de ANA y TDZ reducen el número de plantas regeneradas (Tabla 2; T2, T5 y T6).

Adicionalmente a estos resultados, fue realizado el monitoreo de los cambios morfológicos de estructuras pro-embrionarias a partir de segmentos foliares basales en Phaleanopsis amabilis, sin la adición de ANA y TDZ. Este monitoreo fue realizado desde la formación de callos hasta la transformación en plantas completas (Figura 3). Nuestras observaciones evidencian que segmentos foliares basales tienen alta capacidad embriogénica y las transiciones de cada fase es muy diferenciada hasta obtener la regeneración de plantas completas

\section{IV.DISCUSIÓN}

Mensajeros químicos que regulan el desarrollo en plantas han sido caracterizados ampliamente en plantas, muchas de estas moléculas están dispuestas en bajas concentraciones a nivel endógeno. Sin embargo, su papel es crucial en el desarrollo y organización de órganos. Inducción de la embriogénesis somática en Phaleanopsis no es un tópico nuevo, todos ellos tienen como objetivo generar una metodología capaz de poder clonar plantas completas con características deseables. La formación de callos a partir de segmentos foliares de12 x $1.7 \mathrm{~mm}$ es una contribución nueva en este trabajo de investigación, debido a que en trabajos anteriores se ha utilizado hojas enteras como material de inducción (Chen et al., 2000). El empleo de reguladores de crecimiento como ANA y TDZ también fueron utilizados para la inducción de la embriogénesis somática en Phaleanopsis, sugiriéndose que son necesarios para el proceso de inducción de la embriogénesis somática directa (Chen y Chang, 2001; Gow et al., 2010; Feng y Jen-Tsung et al., 2014). Nuestros resultados, demuestran un escenario distinto, donde segmentos de la región basal y medial de hojas enteras bajo condición endógena (sin la adición de ANA y BAP) poseen la capacidad de inducir callo embriogénico, generar estructuras pro-embrionarias y transformar plantas completas. Probablemente, la dimensión de segmentación de las regiones foliares aquí estudiadas poseen mayor capacidad de estar en contacto con el medio nutritivo y por tanto una mayor respuesta a una condición intrínseca. Observaciones 
similares fueron reportadas cuando se estudió embriogénesis somática directa en segmentos de hoja basal y apical, donde se registró mayor actividad embriogénica para Oncidium y Dendrobium (Chen y Chang 2001; Chung et al., 2005; Chung et al., 2007). Finalmente, nuestros resultados demuestran que segmentos de hoja en Phaleanopsis amabilis dispuestas en menores dimensiones mejoran la capacidad de respuesta embriogénica, y gran parte de su respuesta embriogénica en regiones mediales y basales dependen de su condición fisiológica endógena en un $66,67 \%$. Nuestros resultados que identifican la secuencia de regeneración de plantas vía embriogénesis somática directa pueden ser utilizados como modelo para el estudio de transiciones embrionarias en Phaleanopsis amabilis.

\section{CONCLUSIONES}

Se ha logrado determinar una metodología para la inducción de la embriogénesis somática directa en Phalaenopsis amabilis., a partir de segmentos foliares. Donde el uso de segmentos de hoja basal y medial de 12x1.7 mm sin la adición de ANA y TDZ promueve la capacidad de inducir callo embriogénico, generar estructuras pro-embrionarias y transformar plantas completas.

\section{REFERENCIAS BIBLIOGRÁFICAS}

Arditti, J. y R. Ernst. 1993. Micropropagation of orchids. New Jersey (USA): John Wiley \& Sons.

Chen, Y. y P. Chitrapan. 1995. "Effects of thidiazuron and N6-benzylaminopurine on shoot regeneration of Phalaenopsis". Plant Growth Regulation 16:99-101.

Chen, Y., C. Chang, y C. Chang. 2000. "A reliable protocol for plant regeneration from callus culture of Phalaenopsis". In Vitro Cell Dev Biol Plant 36: 420-423.

Chen, J. y T. Chang. 2001. "Effects of auxins and cytokinins on direct somatic embryogebesis on leaf explants of Oncidium 'Grower Ramsey". Plant Growth Regul 34: 229-232.
Chen, J. T. y W. Chang. 2006. "Direct somatic embryogenesis and plant regeneration from leaf explants of Phalaenopsis amabilis". Biologia Plantarum 50: 169-173.

Chung, H. H., J. T. Jen-Tsung Chen y W. C. Chang. 2005. "Cytokinins induce direct somatic embryogenesis of Dendrobium Chiengmai Pink and subsequent plant regeneration". In Vitro Cellular and Developmental BiologyPlant 41: 765-769.

Chung, H., J. T. Chen y W. C. Chang. 2007. "Plant regeneration through direct somaticembryogenesis from leaf explants of Dendrobium". Biologia plantarum 51: 346350.

Ernst, R. 1994. "Effects of thidiazuron on in vitro propagation of Phalaenopsis and Doritaenopsis (Orchidaceae)". Plant Cell, Tissue and Organ Culture 39: 273-275.

Gil, J.Y. 1987. "The propagation of Phalaenopsis, part II". Malayan Orchid Review 21: 45-46.

Harper, T. 2004. "Phalaenopsis culture: Advice for growing 20 species". Orchids Mag 73: 118127.

Islam, O. M. y I. Syoichi. 1999. "Effects of sucrose, maltose and sorbitol on callus growth and plantlet regeneration in Phalaenopsis, Doritaenopsis and Neofinetia". Journal of the Japanese society for horticultural science 68: 1124-1131.

Ishii, Y., T. Takamura, M. Goi y M. Tanaka. 1998. "Callus induction and somatic embryogenesis of Phalaenopsis". Plant Cell Reports 17: 446450 .

Feng, J. H. y C. Jen-Tsung. 2014. "A novel in vitro protocol for inducing direct somatic embryogenesis in Phalaenopsis aphrodite without taking explants". The Scientific World Journal 2014: 1-7.

Murashige, T. y F. Skoog. 1962. “A revised medium for rapid growth and bio assays with tobacco tissue cultures". Physiologia plantarum 15: 
473-497.

Park, S. Y., H. N. Murthy y K. Y. Paek. 2002. "Rapid propagation of Phalaenopsis from floral stalkderived leaves". In Vitro Cellular \& Developmental Biology-Plant 38: 168-172.

Thorpe, T. A. 1981. Plant tissue culture: methods and applications in agriculture. New York (USA): Academic Press.

Tanaka, M., H. Atsushi y G. Masanori. 1975. "Studies on the clonal propagation of monopodial orchids by tissue culture". Journal of the Japanese Society for Horticultural Science 44: 47-58.

Gow, W. P., J. T. Chen y W. C. Chang. 2010. "Enhancement of direct somatic embryogenesis and plantlet growth from leaf explants of Phalaenopsis by adjusting culture period and explant length". Acta Physiologiae Plantarum 32: 621-627.

Young, P., S. H. Murthy y P. K. Yoeup. 2000. "Mass multiplication of protocorm-like bodies using bioreactor system and subsequent plant regeneration in Phalaenopsis". Plant Cell, Tissue and Organ Culture 63: 67-72. 